\title{
The influence of allogenic blood transfusion in patients having free-flap primary surgery for oral and oropharyngeal squamous
} cell carcinoma

\author{
T Szakmany', M Dodd², GA Dempsey', D Lowe³, JS Brown², ED Vaughan² and SN Rogers*,2 \\ 'Intensive Care Unit, University Hospital Aintree, Liverpool L9 IAL, UK; ${ }^{2}$ Regional Maxillofacial Unit University Hospital Aintree, Fazakerley, Liverpool L9 \\ IAL, UK; ${ }^{3}$ Medical Statistician, Regional Maxillofacial Unit University Hospital Aintree, Fazakerley, Liverpool L9 IAL, UK
}

\begin{abstract}
The influence of perioperative blood transfusion in oral and oropharyngeal squamous cell carcinoma remains uncertain. It is believed that blood transfusion downregulates the immune system and may have an influence on cancer recurrence and survival. In all, 559 consecutive patients undergoing primary surgery for oral and oropharyngeal squamous cell carcinoma between 1992 and 2002 were included in this study. Known prognostic variables along with transfusion details were obtained from head and neck cancer and blood transfusion service databases, respectively. Adjusting for relevant prognostic factors in Cox regression, the hazard ratio for patients having 3 or more transfused units relative to those not transfused was 1.52 (95\% confidence interval (Cl) $0.93-2.47$ ) for diseasespecific and $1.52(95 \% \mathrm{Cl}$ I.05-2.22) for overall mortality. Blood transfusion of 3 or more units might confer a worse prognosis in patients undergoing primary surgery for oral and oropharyngeal squamous cell carcinoma. Therefore, every effort should be made to limit the amount of blood transfused to the minimum requirement.

British Journal of Cancer (2006) 94, 647-653. doi: I0.1038/sj.bjc.66030I3 www.bjcancer.com

(C) 2006 Cancer Research UK
\end{abstract}

Keywords: mouth neoplasm; head and neck cancer; survival; transfusion

Perioperative blood transfusions are reported to be related to cancer recurrence and reduced survival (Werther et al, 2001). Different underlying mechanisms have been proposed, and allogenic leucocytes in transfused blood have been suggested to contribute to this phenomenon (Jensen et al, 1992). The persistence of antigens in the recipient's circulation might also create an environment, which allows immune system downregulation. This possibility was supported by the evidence that allogenic blood transfusion enhances renal allograft survival; however, it has been hypothesised that blood transfusionassociated immune depression might be deleterious in cancer patients (Opelz et al, 1973; Gantt, 1981; Vamvakas and Blajchman, 2001). Although numerous clinical studies have addressed the question of perioperative blood transfusion and cancer recurrence and/or survival, the possibly harmful effect of allogenic blood transfusion on immunomodulation remains unresolved.

To date, there is relatively little published data on blood transfusion and outcome in oropharyngeal cancer (von Doersten et al, 1992; Sturgis et al, 1997; Taniguchi and Okura, 2003). In head and neck cancer, the effect of allogenic blood transfusion has been reported on relatively small numbers of patients with conflicting results (Table 1) (von Doersten et al, 1992; Woolley et al, 1992; Sturgis et al, 1997; Vamvakas and Blajchman, 2001; Taniguchi and Okura, 2003). Some authors have reported deleterious effects of blood transfusion (Jones and Weissler, 1990; Woolley et al, 1992;

*Correspondence: Dr SN Rogers; E-mail: snrogers@doctors.org.uk Received 18 October 2005; revised 23 January 2006; accepted 30 January 2006
Taniguchi and Okura, 2003), while others could not confirm transfusion as an independent predictive factor in multivariate analysis (von Doersten et al, 1992; Schuller et al, 1994). A recent paper by Taniguchi and Okura (2003), specific to oral and oropharyngeal cancer, only showed the outcomes were worse with 3 or more units. This accumulating threshold effect of allogenic blood transfusion has already been seen with colonic and oesophageal cancers (Tartter, 1992; Langley et al, 2002). Hence, we undertook this study to test the hypothesis that perioperative blood transfusion has an adverse effect on survival of patients with oral and oropharyngeal cancer.

\section{MATERIALS AND METHODS}

The study sample consisted of all consecutive patients undergoing primary surgery for previously untreated oral and oropharyngeal squamous cell carcinoma presenting to the Regional Maxillofacial Unit Liverpool, between the years 1992 and 2002. The Liverpool Oncology Head and Neck database was used to gather the clinical, demographic, surgical, pathological and outcome data. The data were downloaded into SPSS for further analyses.

Blood transfusion data were obtained from the centralised transfusion database of the Haematology Department of University Hospital Aintree. Perioperative haemoglobin levels were also collected if available from the computerised laboratory reporting system of the Haematology Department of University Hospital Aintree.

The Office of National Statistics supplied details of death certification for this patient cohort. Four clinicians 
Table I Effect of allogenic blood transfusion in other studies involving head and neck cancer patients

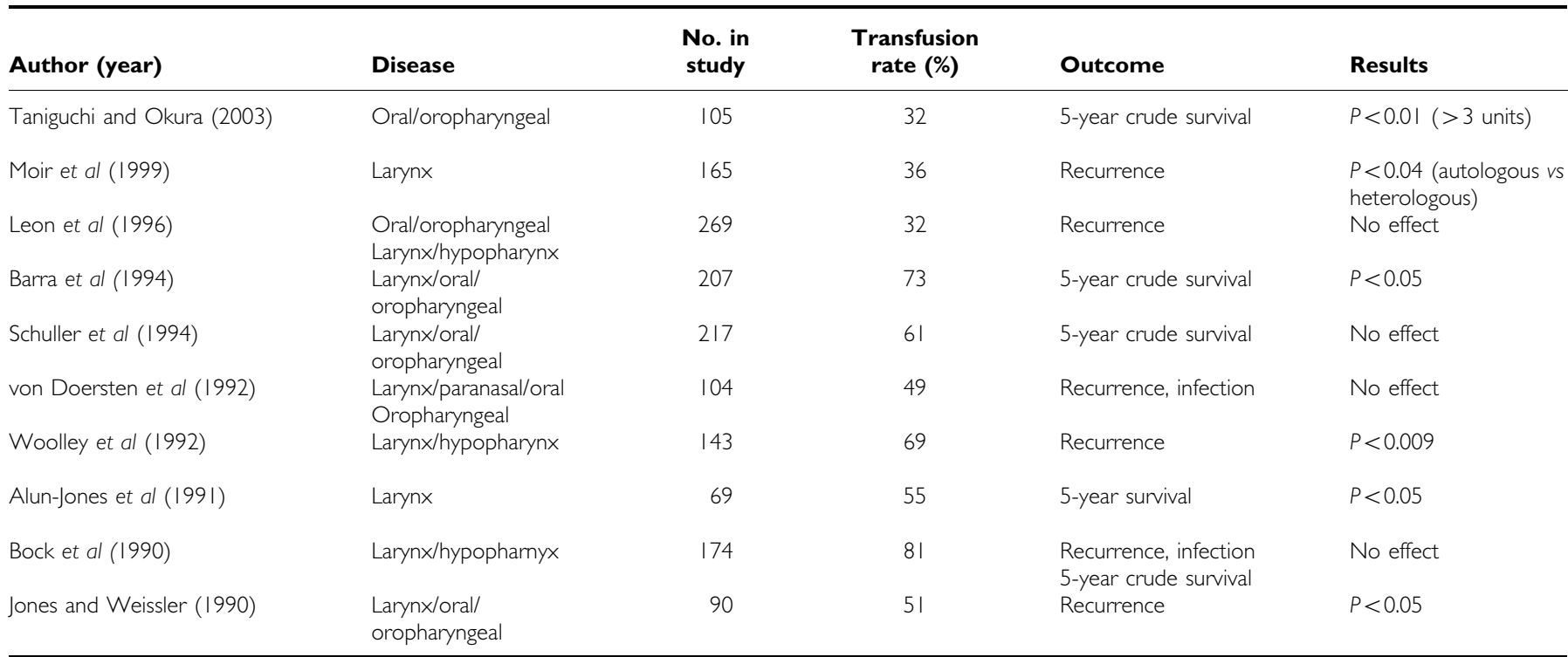

All studies reporting a significant difference do so for worse outcome associated with allogenic blood transfusion.

independently attributed cause of death to oral cancer or other causes. In 10 cases (4\% of deaths), there was a 50:50 judgement and further discussion between clinicians was required to reach a verdict.

\section{Statistical method}

Association of factors with transfusion were tested by the $\chi^{2}$ test. Kaplan-Meier methods were used to estimate oral cancer diseasespecific survival by patient groups and the log-rank test was used to compare survival curves. Cox regression methods were used to estimate the association of transfusion, and of transfusion with 3 or more units of blood, on survival after adjusting for covariates. The 95\% confidence intervals for unadjusted and adjusted hazard ratios were obtained. Survival curve results were stratified by tumour $p$ stage and adjusted Cox regression hazard ratios obtained. Stepwise Cox regression was used to find the best-fitting survival model from all available covariates and the linear prediction from this model was used to place patients into similarly sized 'lower' and higher' mortality risk groups. Survival curves by transfusion status were compared within these risk groups, and hazard ratios adjusted for the prognostic factors were also computed. The cutoff at 3 units of transfused blood was chosen to match the paper of Taniguchi and Okura (2003).

The preoperative haemoglobin cutoff value of $10 \mathrm{~g} \mathrm{dl}^{-1}$ was set according to existing transfusion guidelines. Preoperation haemoglobin levels were routinely recorded from 1997 and were not included in the main prognostic analyses from 1992, but were included in separate analyses of the data from 1999 to 2002, analyses specifically undertaken to assess the situation following the adoption of leuco-depletion of blood in Aintree Hospitals from January 1999.

\section{RESULTS}

The cohort comprised 559 patients undergoing primary surgery from 1992 to 2002 for previously untreated oral and oropharyngeal squamous cell carcinoma. Almost all (96\%, 1342 of 1397) transfused units of blood during this time were for 437 patients having free-flap surgery. During the operation, $77 \%$ (337 of 437) were transfused with blood and 68\% (223 of 330) of these received 3 or more units of blood, units unknown for seven patients. Transfusion rates per se, and rates for transfusions with 3 or more units, were highest for free-flap surgery patients with more advanced stages of disease, when soft-tissue margins were involved, with perineural invasion, for segmental resection and for composite-flap surgery (Table 2).

The 5-year Kaplan-Meier estimate of oral cancer survival for patients receiving blood was $67 \%$ (s.e. $3 \%$ ) as compared with $78 \%$ (s.e. 3\%) for those not transfused. The relative risk of death (hazard ratio) from patients having a blood transfusion alone was estimated from Cox regression to be 1.59 (95\% confidence interval (CI) $1.00-2.54)$. There was little difference in survival between those having no transfusions and those having 1 or 2 units transfused, but there was worse survival in those having 3 or more units transfused (Figure 1). The hazard ratio for patients with 3 or more transfused units was 1.93 (95\% CI $1.20-3.11)$ relative to those not transfused.

Many clinical and pathological factors were associated with disease-specific survival (Table 3) and there was inter-correlation between pathological factors. Patients having 3 or more units had the worse survival for both $\mathrm{p} 1-2$ and $\mathrm{p} 3-4$ stage tumours (Figure 2), and adjusting for $\mathrm{p}$ stage in Cox regression gave hazard ratios of 1.35 (95\% CI $0.84-2.16)$ for transfusion and $1.56(95 \% \mathrm{CI}$ $0.96-2.52)$ for transfusion with 3 or more units. When all factors (of Table 3 ) were entered into a stepwise Cox regression $(P<0.01$ for entry), the two predictors selected were $\mathrm{pN}$ status and margins. The linear prediction from the regression model was used to place patients into similarly sized lower and higher risk groups. In effect, the lower risk group comprised 221 patients either with clear margins and $\mathrm{pN} 0 / \mathrm{pN} 1$ or with close margins and $\mathrm{pN} 0$. Within each risk group, patients with 3 or more transfused units had the worst survival (Figure 3). Adjusting for $\mathrm{pN}$ status and margins in Cox regression gave a hazard ratio of 1.29 (95\% CI $0.80-2.08)$ for transfusion and $1.52(95 \%$ CI $0.93-2.47)$ for transfusion with 3 or more units.

All-cause mortality rates for patients receiving blood was $48 \%$ (s.e. $3 \%$ ) as compared with $65 \%$ (s.e. $5 \%$ ) for those not transfused. We found the same univariate predictors of all-cause mortality as for disease specific (data not shown). Cox regression gave unadjusted hazard ratios of 1.61 for transfusion and 1.84 for 
Table 2 Association of factors with blood transfusion for patients having free-flap surgery

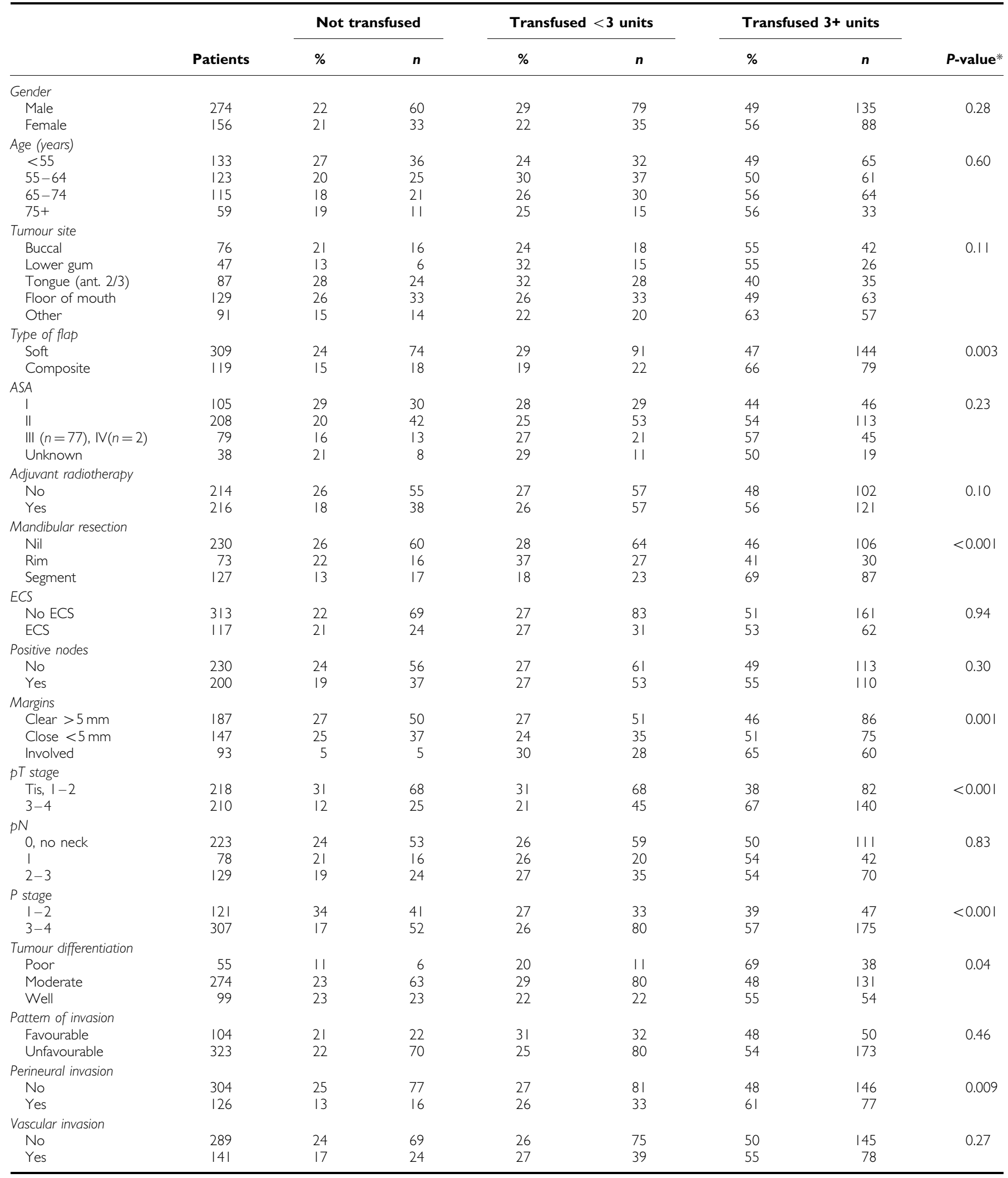

$\mathrm{ASA}=$ American Society of Anesthesiologists; $\mathrm{ECS}=$ extracapsular spread. * $\chi^{2}$ test. Note the table excludes seven patients who had transfusions, but the number of units was unknown. T and $\mathrm{N}$ stage: Tis is in situ, 1 is $2 \mathrm{~cm}$ or less, 2 is more than $2 \mathrm{~cm}$ upto $4 \mathrm{~cm}, 3$ is more than $4 \mathrm{~cm}$ up to $6 \mathrm{~cm}, 4$ is greater than $6 \mathrm{~cm}$ or involving adjacent structures. Nodal stage: NO: No evidence of regional lymph node metastasis. NI: Metastasis in a single ipsilateral (same side) lymph node, $3 \mathrm{~cm}$ or less in size. N2: Metastasis in a single ipsilateral (same side) lymph node more than $3 \mathrm{~cm}$ but not more than $6 \mathrm{~cm}$ in greatest dimension, or metastasis in multiple ipsilateral (same side) lymph nodes, none more than $6 \mathrm{~cm}$ in greatest dimension, or metastasis in bilateral (both) or contralateral (opposite side) lymph nodes, none more than $6 \mathrm{~cm}$ in greatest dimension. N3: Metastasis in a lymph node more than $6 \mathrm{~cm}$ in greatest dimension. $\mathrm{P}$ stage is a combination of $\mathrm{T}$ and $\mathrm{N}$ status. 


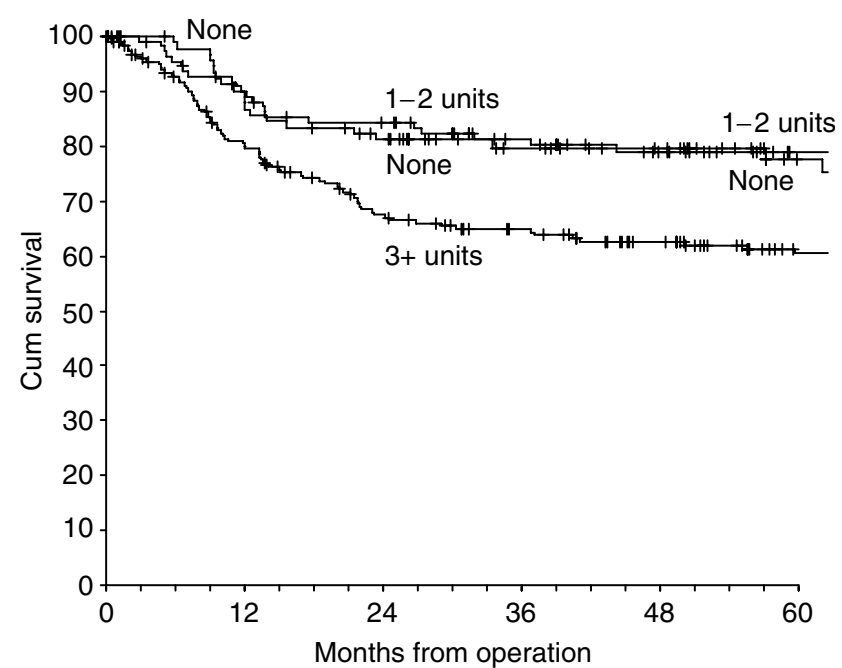

Figure I Kaplan-Meier disease-specific survival by whether patients had no blood transfusion, were transfused with $1-2$ units or transfused with 3 or more units of blood.

transfusion of 3 or more units, and adjustment for $\mathrm{pN}$ status, margins, age and perineural invasion (independent predictors at $P<0.01)$ gave hazard ratios of 1.35 (95\% CI $0.94-1.93)$ for transfusion and $1.52(95 \%$ CI $1.05-2.22)$ for transfusion with 3 or more units.

Preoperation haemoglobin levels were routinely recorded from 1997 and were known for $81 \%$ (190 of 234). Transfusion rates were $81 \%$ (43 of 53) for patients with haemoglobin levels of 10 and under and $70 \%$ (95 of 136) for levels over 10. Rates for transfusion with 3 or more units were $47 \%$ (25 of 53 ) and 39\% (53 of 136), respectively. The 5-year disease-specific survival rates were $65 \%$ (s.e. 7) and 78 (s.e. 4), $P=0.19$, and for all-cause survival, $44 \%$ (s.e. 7) and $60 \%$ (s.e. 5), $P=0.07$. The mean (s.d.) haemoglobin level was 12.2 (2.3) for patients not transfused, 11.9 (2.6) for those transfused 1-2 units and 11.3 (2.3) for those transfused 3 or more units. For patients transfused with 3 or more units, the observed disease-specific survival was worse for those with preoperative haemoglobin levels of $\leqslant 10$ (Figure 4), unadjusted hazards ratio $1.71(95 \%$ CI $0.79-3.68)$ and after adjustment for $\mathrm{pN}$ status and margins 1.92 (95\% CI $0.87-4.27)$.

From the beginning of January 1999, leuco-depletion of blood was introduced at University Hospital Aintree. In separate analyses of the data from 1999 for disease-specific survival, Cox regression methods gave unadjusted hazard ratios of 1.72 for transfusion and 2.22 for transfusion of 3 or more units, and after adjustment ( $\mathrm{pN}$ status and margins), 1.34 (95\% CI $0.63-2.85$ ) for transfusion and 2.09 (95\% CI $0.94-4.78)$ for 3 or more units. For all-cause survival, adjusted ( $\mathrm{pN}$ status, margins, age and perineural invasion) ratios were $1.48(95 \%$ CI $0.81-2.68)$ and 1.60 (95\% CI $0.82-3.11)$.

Transfusion rates have fallen over time, $86 \%$ (239 of 279) before 1999 and 65\% (98 of 151) from 1999 to 2002. Rates for transfusion with 3 or more units were 59\% (165 of 279) and 38\% (58 of 151), respectively. Before 1999, 5-year disease-specific survival was $68 \%$ (s.e. 3) and overall survival 51\% (3), whereas from 1999 to 2002, 5year disease-specific survival was $72 \%$ (s.e. 4 ) and overall survival $48 \%$ (5).

In the whole cohort, there was a higher rate of recurrence for patients transfused with 3 or more units $(29 \%, 65$ of 223) than for patients transfused with 1-2 units (19\%, 22 of 114) and for patients not transfused $(19 \%, 18$ of 93$) P=0.06 \chi^{2}$ test. Local-only recurrence rates were $14 \%$ ( 31 of 222 ), $8 \%$ (nine of 114 ) and $6 \%$ (six of 93), respectively, $P=0.08$.
Table 3 Association of factors with disease-specific survival for patients having free-flap surgery

\begin{tabular}{|c|c|c|c|c|}
\hline & \multirow[b]{2}{*}{ Patients } & \multicolumn{3}{|c|}{ Disease specific } \\
\hline & & 2 years & 5 years & $P$-value* \\
\hline \multicolumn{5}{|l|}{ Blood transfusion } \\
\hline No & 93 & 81 & 79 & \multirow[t]{3}{*}{0.001} \\
\hline$<3$ units & 114 & 84 & 79 & \\
\hline $3+$ units & 223 & 67 & 61 & \\
\hline \multicolumn{5}{|l|}{ Gender } \\
\hline Male & 279 & 76 & 71 & \multirow[t]{2}{*}{0.29} \\
\hline Female & 158 & 72 & 65 & \\
\hline \multicolumn{5}{|l|}{ Age (years) } \\
\hline$<55$ & 137 & 80 & 76 & \multirow[t]{4}{*}{0.008} \\
\hline $55-64$ & 125 & 73 & 66 & \\
\hline $65-74$ & 115 & 77 & 75 & \\
\hline $75+$ & 60 & 58 & 50 & \\
\hline \multicolumn{5}{|l|}{ Tumour site } \\
\hline Buccal & 76 & 74 & 69 & \multirow[t]{5}{*}{0.51} \\
\hline Lower gum & 47 & 79 & 74 & \\
\hline Tongue (ant. 2/3) & 91 & 71 & 67 & \\
\hline Floor of mouth & 132 & 78 & 73 & \\
\hline Other & 91 & 72 & 64 & \\
\hline \multicolumn{5}{|l|}{ ASA } \\
\hline 1 & 109 & 81 & 79 & \multirow[t]{4}{*}{0.07} \\
\hline$\|$ & 210 & 74 & 66 & \\
\hline II/IV & 80 & 71 & 64 & \\
\hline Unknown & 38 & 68 & 62 & \\
\hline \multicolumn{5}{|l|}{ Type of flap } \\
\hline Soft & 316 & 76 & 71 & 0.29 \\
\hline Composite & 119 & 71 & 66 & \\
\hline Adjuvant radiotherapy & & & & \\
\hline No & 220 & 81 & 77 & 0.002 \\
\hline Yes & 217 & 69 & 62 & \\
\hline Mandibular resection & & & & \\
\hline Nil & 237 & 77 & 73 & 0.11 \\
\hline $\operatorname{Rim}$ & 73 & 79 & 70 & \\
\hline Segment & 127 & 68 & 63 & \\
\hline ECS & & & & \\
\hline No ECS & 320 & 83 & 77 & $<0.001$ \\
\hline ECS & 117 & 52 & 46 & \\
\hline Positive nodes & & & & \\
\hline No & 237 & 86 & 81 & $<0.001$ \\
\hline Yes & 200 & 61 & 55 & \\
\hline Margins & & & & \\
\hline Clear $>5 \mathrm{~mm}$ & 192 & 89 & 84 & $<0.001$ \\
\hline Close $<5 \mathrm{~mm}$ & 149 & 71 & 64 & \\
\hline Involved & 93 & 50 & 46 & \\
\hline pT stage & & & & \\
\hline Tis, I-2 & 224 & 82 & 77 & $<0.001$ \\
\hline $3-4$ & 211 & 66 & 61 & \\
\hline pN & & & & \\
\hline 0 , no neck & 230 & 87 & 82 & $<0.001$ \\
\hline 1 & 78 & 73 & 68 & \\
\hline $2-3$ & 129 & 53 & 47 & \\
\hline$P$ stage & & & & \\
\hline $1-2$ & 127 & 90 & 86 & $<0.001$ \\
\hline $3-4$ & 308 & 68 & 62 & \\
\hline Tumour differentiation & & & & \\
\hline Poor & 55 & 58 & 52 & $<0.001$ \\
\hline Moderate & 279 & 72 & 66 & \\
\hline Well & 100 & 89 & 87 & \\
\hline Pattern of invasion & & & & \\
\hline Favourable & 105 & 91 & 88 & $<0.001$ \\
\hline Unfavourable & 329 & 69 & 63 & \\
\hline Perineural invasion & & & & \\
\hline No & 307 & 80 & 74 & $<0.001$ \\
\hline Yes & 130 & 60 & 56 & \\
\hline Vascular invasion & & & & \\
\hline No & 294 & 82 & 76 & $<0.001$ \\
\hline Yes & 143 & 60 & 54 & \\
\hline
\end{tabular}

ASA = American Society of Anesthesiologists; ECS = extracapsular spread. *Log-rank test. Table gives 2- and 5-year Kaplan-Meier survival rates. 
P stage 1-2

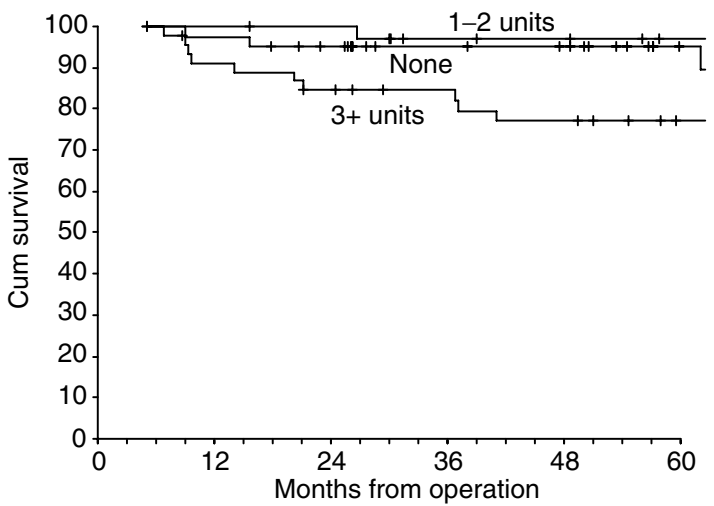

Patient numbers: None $(n=41), 1-2$ units $(n=33), 3+$ units $(n=47)$

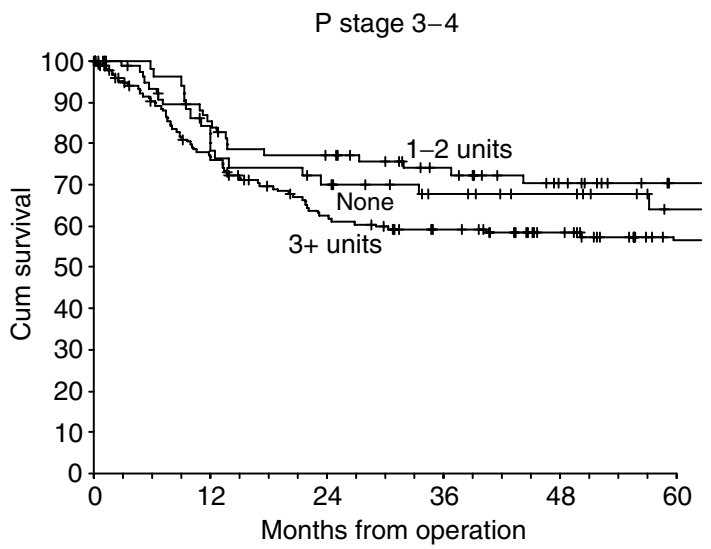

Patient numbers: None ( $n=52), 1-2$ units $(n=80), 3+$ units $(n=175)$

Figure 2 Kaplan-Meier disease-specific survival by blood transfusion and $\mathrm{p}$ stage.

\section{DISCUSSION}

In this large cohort of patients with oral and oropharyngeal cancer, the biggest influences on disease-specific and all-cause mortality were related to tumour pathology, resection margins and nodal status. Death certification was used to help give an indication as to the cause of death and help determine disease-specific survival. Although death certification in the absence of post mortem has its limitations owing to reporting errors, it has been shown to be of value in this cancer group (Leitner et al, 2001). Mortality was observed to be higher among patients receiving allogenic blood transfusion and higher still for those receiving 3 or more units. This association persisted after adjusting for confounding factors. These results were in keeping with those from previous authors, but were at the borderline of statistical significance (von Doersten et al, 1992; Woolley et al, 1992; Vamvakas and Blajchman, 2001; Taniguchi and Okura, 2003).

In the management of oral and oropharyngeal cancer prolonged surgical procedures involving tumour resection and reconstruction using free tissue transfer techniques will frequently result in significant intraoperative blood loss. Reported transfusion rates have varied widely from 32 to $81 \%$, with more recent studies reporting lower transfusion rates (Taniguchi and Okura, 2003). This is in keeping with our experience, we observed a halving in transfusion rate from $88 \%$ in 1992 to $44 \%$ in 2002 . It might be that more recent patients who have transfusion are more anaemic than patients earlier in the series. Hence, preoperative anaemia

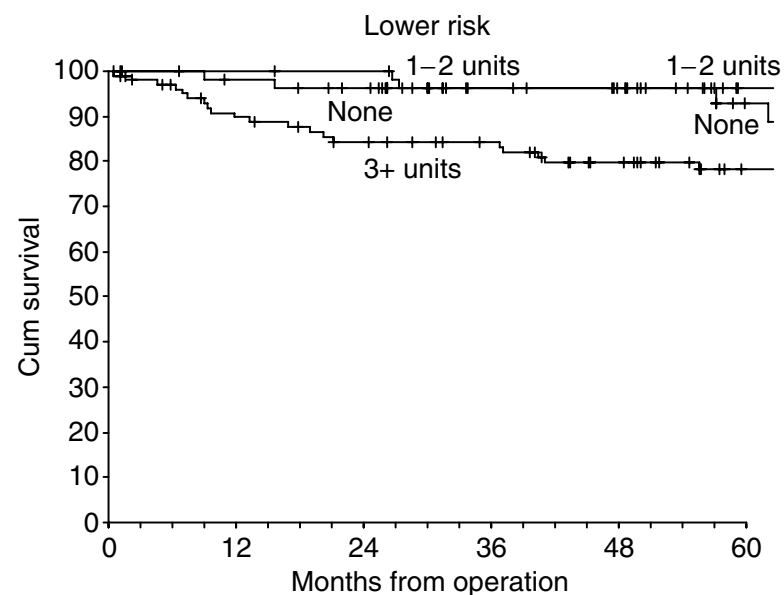

Patient numbers: None ( $n=56), 1-2$ units $(n-55), 3+$ units $(n=103)$

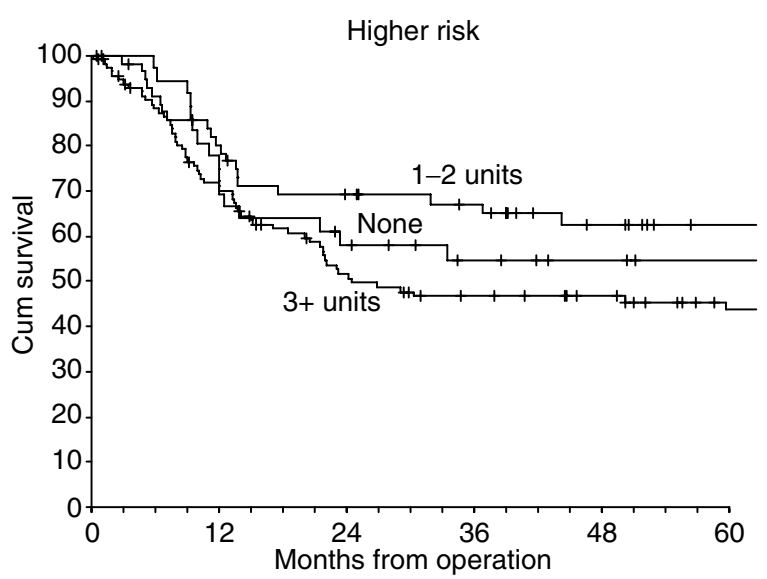

Patient numbers: None ( $n=36), 1-2$ units $(n=59), 3+$ units $(n=115)$

Figure 3 Kaplan-Meier disease-specific survival by blood transfusion and risk group (derived from Cox regression based on $\mathrm{pN}$ status and margins).

associated with transfusion may explain the enhanced hazard ratios from 1999 onwards. However, we cannot properly analyse the whole cohort, with respect to properative anaemia, owing to the lack of haemoglobin data prior to 1997. Survival is affected by several factors including malignancy stage, tumour resection margins and chronic systemic illness, all of which are confounding factors for allogenic blood transfusion (de Cassia Braga Ribeiro et al, 2003). A recent meta-analysis, which summarised findings of several observational studies, failed to show any significant outcome benefit between transfused and nontransfused patients (Vamvakas and Blajchman, 2001). Transfusion itself was associated with a 2.5 -fold increase in mortality before adjustment for other factors, similar to our results presented above. In contrast to Vamvakas, however, our data suggest that transfusion of 3 or more units of blood is associated with a worse outcome in oropharyngeal cancer patients, with a reduction in survival and an increase in recurrence rates. Our data reinforce those of Taniguchi who observed an almost five-fold increase in the risk of death among patients transfused more than 3 units of blood compared to nontransfused patients (Taniguchi and Okura, 2003). Our data suggest that transfusion of 3 or more units of blood could confer a worse 5-year survival in oral cancer patients. Our patients were stratified into high- and low-risk groups, with this effect being observed in both groups (Figures 2 and 3). It seems, although more advanced disease carries a significantly worse prognosis, blood transfusion itself may accentuate this deleterious effect. To clearly 


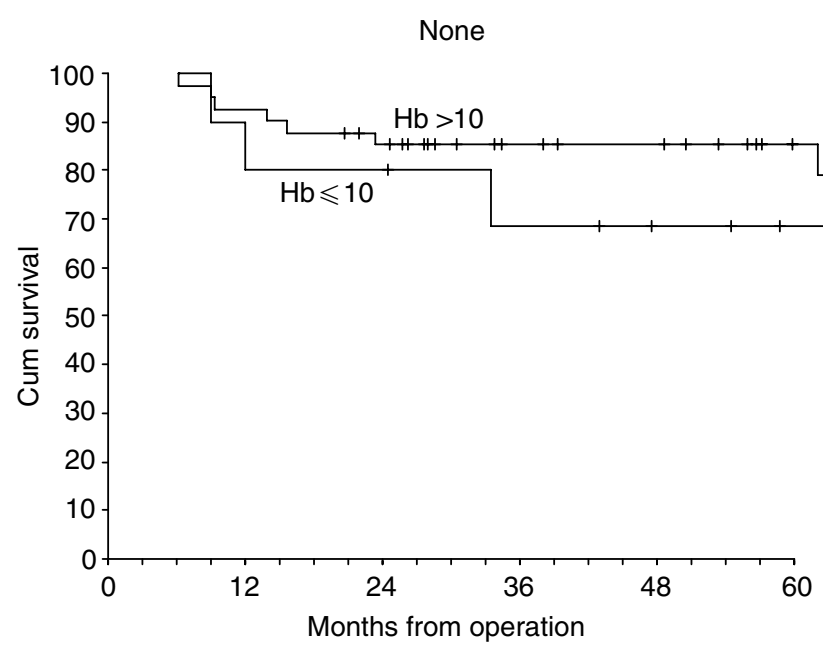

Patient numbers: $\mathrm{Hb} \leqslant 10(n=10), \mathrm{Hb}>10(n=41)$

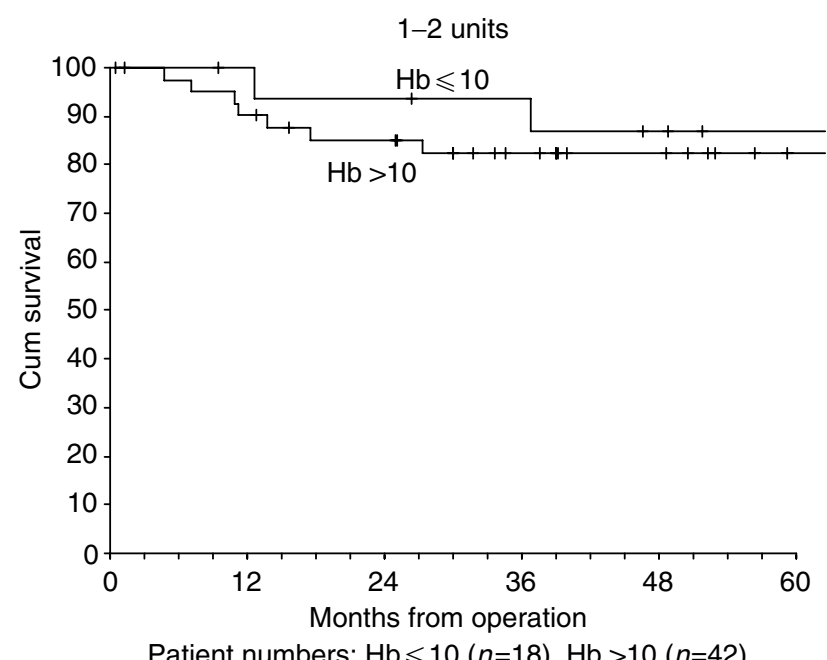

Patient numbers: $\mathrm{Hb} \leqslant 10(n=18), \mathrm{Hb}>10 \quad(n=42)$

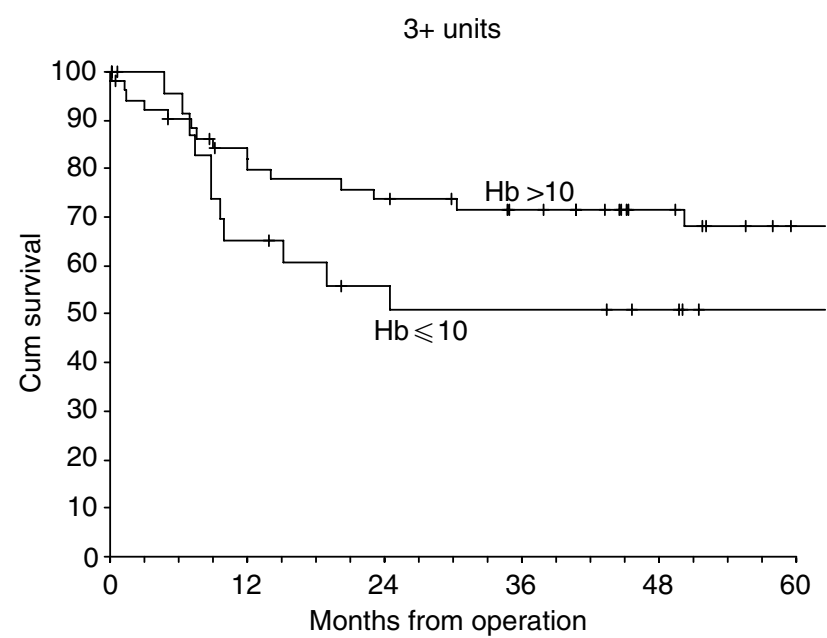

Patient numbers: $\mathrm{Hb} \leqslant 10(n=25), \mathrm{Hb}>10(n=53)$

Figure 4 Kaplan-Meier disease-specific survival by blood transfusion and preoperation haemoglobin level.

answer the question whether blood transfusion affects survival, a randomised controlled trial is required. This would need to be multicentre and would involve withholding blood or blood products.
To date, clinical trials are inconclusive as to whether tumour recurrence rate is higher after transfusion in head and neck cancer (Jones and Weissler, 1990; Sturgis et al, 1997). Our study suggests that the local and systemic cancer recurrence rate is higher in those patients who were transfused with 3 or more units of blood. Given that the volume of blood transfused appears to be of prime importance in this worsened outcome, it is likely that the underlying cause is a dose-related immune suppression. The earliest reports of immunomodulation after blood transfusion in the 1970s were in the field of renal transplantation where transfusion before transplantation was accompanied with an improved allograft survival (Opelz et al, 1973; Opelz and Terasaki, 1978). Improved graft survival is associated with an increasing number of transfusions before transplantation, with a near maximal benefit after 5 units (Opelz and Terasaki, 1978). These data suggest that there may be an immunomodulatory threshold effect related to volume of blood transfused. In the context of cancer surgery, a similar finding has been demonstrated in that the adverse influence of blood transfusion on survival is seen only after larger transfusions for colorectal tumours, soft-tissue sarcomas and oesophageal cancers (Rosenberg et al, 1985; Tartter, 1992; Langley et al, 2002). Our results would appear to support the existence of a threshold effect, which has been demonstrated previously (Langley et al, 2002; Taniguchi and Okura, 2003).

Transfusion-related immunosuppression consists of a monocyte-mediated early phase and a later phase, which is characterised by increased suppressor T-cell activity. Both effects appear to be dependent on the number of transfusions (Dellinger and Anaya, 2004). Allogenic blood transfusion has been shown to impair natural killer cell function and also inhibit interleukin-2 production, both mechanisms crucial for normal antitumour activity (Dellinger and Anaya, 2004).

Although it is not entirely clear at molecular level which factors modulate the effects of allogenic blood transfusion in cancer surgery, there is good evidence that leucocytes in the blood mediate them (Jensen et al, 1992).

The patients in the current study did not have leukocytedepleted transfusions until 1999, since when all allogenic blood for transfusion in our hospital has been leucocyte depleted. This is part of a nationwide policy in the United Kingdom aimed at minimising the possibility of variant Creutzfeldt-Jakob disease being passed through transfusion of blood orblood products. Although most of the possible detrimental effects of blood transfusion are thought to be mediated via the transfused leucocytes, we were unable to find any significant differences in the clinical outcome of patients before and after the leucocyte depletion policy was implemented.

It has been postulated that preoperative haemoglobin levels are independent predictors of survival in head and neck cancer (Macdonald and Hurman, 2004). In our series, we observed that patients who received 3 or more units of blood and had low preoperative haemoglobin had worse survival compared to those who had normal haemoglobin levels (Figure 4). This effect was less marked among those patients who received only 1-2 units of blood (Figure 4). This may suggest that patients whose disease is more advanced and manifests in severe preoperative anaemia mainly owing to reduced oral intake and dietary problems are much more vulnerable to the deleterious immunosuppressive effects of a larger allogenic blood transfusion.

Despite the limitations of the current study, including its retrospective nature, the results support previous work that demonstrated an adverse effect on survival of patients undergoing resection for oral carcinoma who receive an allogenic blood transfusion (Woolley et al, 1992; Taniguchi and Okura, 2003). Clinical trials with erythropoietin and acute normovolaemic haemodilution have shown promising results in the reduction of allogenic blood product requirements in maxillofacial surgery; however, the importance of the meticulous surgical technique 
cannot be overemphasised (Scott et al, 2002; Habler et al, 2004). Clinicians must be cognizant of the 3 unit threshold and should attempt to limit transfusion volume whenever it is safe to do so.

In conclusion, this study reaffirms the importance of completeness of resection and the importance of lymph node involvement in resection for oral carcinoma. In addition, it suggests that transfusion of 3 or more units of blood could adversely affect

\section{REFERENCES}

Alun-Jones T, Clarke PJ, Morrissey S, Hill J (1991) Blood transfusion and laryngeal cancer. Clin Otaolayngol 16: 240-244

Barra S, Barzan L, Maione A (1994) Blood transfusion and other prognostic variables in the survival of patients with cancer of the head and neck. Laryngoscope 104: 95-98

Bock M, Greavers G, Koblitz M, Heim MU, Mempel W (1990) Influence of blood transfusion on recurrence, survival and postoperative infections of laryngeal cancer. Acta Otolaryngol 110: 155-160

de Cassia Braga Ribeiro K, Kowalski LP, Latorre Mdo R (2003) Perioperative complications, comorbidities, and survival in oral or oropharyngeal cancer. Arch Otolaryngol Head Neck Surg 129: $219-228$

Dellinger EP, Anaya DA (2004) Infectious and immunologic consequences of blood transfusion. Crit Care 8(Suppl 2): S18-S23

Gantt CL (1981) Red blood cells for cancer patients. Lancet 2: 363

Habler O, Schwenzer K, Zimmer K, Prager M, Konig U, Oppenrieder K, Pape A, Steinkraus E, Reither A, Buchrot A, Zwissler B (2004) Effects of standardized acute normovolemic hemodilution on intraoperative allogeneic blood transfusion in patients undergoing major maxillofacial surgery. Int J Oral Maxillofac Surg 33: 467-475

Jensen LS, Andersen AJ, Christiansen PM, Hokland P, Juhl CO, Madsen G, Mortensen J, Moller-Nielsen C, Hanberg-Sorensen F, Hokland M (1992) Postoperative infection and natural killer cell function following blood transfusion in patients undergoing elective colorectal surgery. Br J Surg 79: $513-516$

Jones KR, Weissler MC (1990) Blood transfusion and other risk factors for recurrence of cancer of the head and neck. Arch Otolaryngol Head Neck Surg 116: $304-309$

Langley SM, Alexiou C, Bailey DH, Weeden DF (2002) The influence of perioperative blood transfusion on survival after esophageal resection for carcinoma. Ann Thorac Surg 73: 1704-1709

Leitner C, Rogers SN, Lowe D, Magennis P (2001) Death certification in patients treated by primary surgery for oral and oro-pharyngeal carcinoma: 1992 - 1997. Brit J Oral Maxillofac Surg 39: 204- 209

Leon X, Quer M, Luz Maestre M, Burguers J, Muniz E, Madoz P (1996) Blood transfusion in laryngeal cancer: effect on prognosis. Head and Neck 18: $218-224$

Macdonald G, Hurman DC (2004) Influence of anaemia in patients with head and neck cancer receiving adjuvant postoperative radiotherapy in the Grampian region. Clin Oncol (R Coll Radiol) 16: 63-70 survival. Therefore, every effort should be made to limit the amount of blood transfused to the minimum requirement.

\section{ACKNOWLEDGEMENTS}

We thank Heamatology Department, in particular Dr Barrie Woodcook, University Hospital Aintree.
Moir MS, Samy RN, Hanasono MM, Terris DJ (1999) Autologous and heterologous blood transfusion in head and neck cancer surgery. Arch Otolaryngol Head Neck Surg 125: 864-868

Opelz G, Sengar DP, Mickey MR, Terasaki PI (1973) Effect of blood transfusions on subsequent kidney transplants. Transplant Proc 5: 253 - 259

Opelz G, Terasaki PI (1978) Improvement of kidney-graft survival with increased numbers of blood transfusions. $N$ Engl J Med 299: 799-803

Rosenberg SA, Seipp CA, White DE, Wesley R (1985) Perioperative blood transfusions are associated with increased rates of recurrence and decreased survival in patients with high-grade soft-tissue sarcomas of the extremities. I Clin Oncol 3: 698-709

Schuller DE, Scott C, Wilson KM, Freer R, al-Sarraf M, Jacobs J, Ahmad K, Casiano R, Laramore G (1994) The effect of perioperative blood transfusion on survival in head and neck cancer. Arch Otolaryngol Head Neck Surg 120: $711-716$

Scott SN, Boeve TJ, McCulloch TM, Fitzpatrick KA, Karnell LH (2002) The effects of epoietin alfa on transfusion requirements in head and neck cancer patients: a prospective, randomized, placebo-controlled study. Laryngoscope 112: 1221 - 1229

Sturgis EM, Congdon DJ, Mather FJ, Miller RH (1997) Perioperative transfusion, postoperative infection, and recurrence of head and neck cancer. South Med J 90: 1217-1224

Taniguchi Y, Okura M (2003) Prognostic significance of perioperative blood transfusion in oral cavity squamous cell carcinoma. Head Neck 25: $931-936$

Tartter PI (1992) The association of perioperative blood transfusion with colorectal cancer recurrence. Ann Surg 216: 633-638

Vamvakas EC, Blajchman MA (2001) Deleterious clinical effects of transfusion-associated immunomodulation: fact or fiction? Blood 97: 1180-1195

von Doersten P, Cruz RM, Selby JV, Hilsinger Jr RL (1992) Transfusion, recurrence, and infection in head and neck cancer surgery. Otolaryngol Head Neck Surg 106: $60-67$

Werther K, Christensen IJ, Nielsen HJ (2001) The association between preoperative concentration of soluble vascular endothelial growth factor, perioperative blood transfusion, and survival in patients with primary colorectal cancer. Eur J Surg 167: 287-292

Woolley AL, Hogikyan ND, Gates GA, Haughey BH, Schechtman KB, Goldenberg JL (1992) Effect of blood transfusion on recurrence of head and neck carcinoma. Retrospective review and meta-analysis. Ann Otol Rhinol Laryngol 101: 724-730 